\title{
Experimental investigations on air side heat and mass transfer phenomena in evaporative condensers
}

\author{
Maria Fiorentino $^{1 *}$, Giuseppe Starace ${ }^{2}$ \\ ${ }^{1}$ Decsa S.R.L., Voghera 27058, Italy \\ ${ }^{2}$ Department of Engineering for Innovation, University of Salento, Lecce 73100, Italy
}

Email: fiorentino@decsa.eu

\begin{abstract}
The evaporative cooling is an energy saving technology and for this reason is widely used both in industrial and civil fields. The heat and mass transfer phenomena occurring inside their tube banks are hard to study and even if many researchers have faced them, further activities need to be carried out. For this reason, this work aims at investigating with an experimental approach the evaporative condensers performance at the tube scale, focusing on the air side where more complex physical interactions occur. A test rig has been set up made of a rectangular transparent channel where electrical heaters simulate the refrigerant side and embedded Pt100 Resistance Temperature Detectors controlled by a PID set and keep constant a given outer surface temperature. Water and air operating conditions are controlled as well, and this allows to carry out a sensitivity analysis depending on all the parameters influencing those thermo-fluid dynamic phenomena. The results show that the cooling rate decreases with the air relative humidity and dry bulb temperature, while increases with water flow rate and temperature. For the testing cases the maximum improvements deriving from increasing water flow rate and temperature are of $37 \%$ and $14 \%$ respectively.
\end{abstract}

Keywords: Thermo-fluid Dynamic Analysis, Evaporative Condensers, Experimental Tests, Heat Rejection, Test Bench.

\section{INTRODUCTION}

Due to higher heat transfer coefficients per unit area, lower condensing temperature, reduced water consumption and pumping power, the evaporative condensers are characterized by better performance and lower operational costs compared to dry condensing units and water condensers associated with cooling towers.

Actually, they operate at lower condensing temperature leading to a higher Coefficient of Performance.

The advantages of the evaporative cooling have been investigated by many researchers.

Parker and Treybal [1] carried out experimental activities on counter flow evaporative coolers and obtained relationships for the heat and mass transfer coefficients.

Mizushina et al. [2] characterized three heat transfer geometries, corresponding to different tube diameters, determining empirical heat and mass transfer coefficients correlations for each one.

Kreid et al. [3], Leidenfrost and Korenic [4] studied the influence of fins on the performance of evaporative coolers and condensers, demonstrating that the increased surface improves the heat transfer only if it is completely wet.

Bykov et al. [5] analyzed the water temperature and air enthalpy variations depending on the elevations above the water basin.

Webb [6] modeled cooling towers, evaporative coolers and condensers: he concluded that the water film temperature can be considered constant.

Erens and Dreyer [7] developed a numerical model, valid for any geometry and flow arrangement, to simulate evaporative coolers and condensers.

Zalewski and Gryglaszewski [8] proposed a mathematical model for counter-current evaporative coolers and validated the results with experimental data.

Ettouney et al. [9] tested condensers operating under dry or wet conditions and compared their performance. They studied the influence of the condensing temperature and the water-to-air mass flow ratio.

Qureshi and Zubair [10] modeled evaporative coolers and condensers and studied the effect of fouling and concluded introducing [11] a fouling factor in their models.

In their further work Qureshi and Zubair [12] carried out a sensitivity analysis on evaporative coolers and condensers and detected the process fluid flow rate as the most affecting parameter for the former and the condensing temperature and relative humidity for the latter.

Hajidavaloo and Eghtedari [13] demonstrated how the evaporative cooling reduces power consumption, by substituting the air condenser with an evaporative condenser 
in an air conditioning system. The experimental data showed that the power consumption could be reduced up to $20 \%$, while the COP could be improved up to $50 \%$.

Jahangeer et al. [14] modeled a single straight tube of evaporative condenser using finite differences technique and investigated on heat transfer coefficients.

Tissot et al. [15] investigated the improvement on the heat transfer obtained by spraying water on the tube surface of an air condenser. They noticed that the COP could be improved up to $29 \%$ under defined conditions.

Islam et al. [16] modeled an air conditioning system operating with an evaporative condenser and compared the results with experimental data.

Fiorentino and Starace [17] presented a two-dimensional numerical model of the falling film evaporation on horizontal tubes in evaporative condensers. They detected two different types of flow, depending on the water-to-air mass flow ratio and the tubes arrangement.

Junior and Smith-Schneider [18] built up a small scale evaporative condenser. The collected data (40 samples) were used to predict the rejected heat as a function of condensing temperature, dry and wet bulb temperatures, spray water temperature and water-to-air mass flow ratio.

Their model is characterized by a correlation factor of $79.3 \%$ and a maximum error of $13.28 \%$.

Liu et al. [19] investigated the cooling performance of an air conditioning system using a dual evaporative condenser. They observed that the COP increased with the air velocity and the water spray rate, while it decreased with ambient dry bulb temperature and compressor frequency.

The cooling capacity of the evaporative condenser is influenced by many parameters, which have to be handled in order to carry out a sensitivity analysis.

The test rig described by Fiorentino and Starace [20] allows to control all the affecting factors, such as the outer tube temperature, the water mass flow rate and temperature, the incoming air flow rate, dry bulb temperature and relative humidity.

The relevant results are presented in this work.

\section{THE EXPERIMENTAL CAMPAIGN}

\subsection{The setup}

The experimental setup is schematized in Figure1.

A test bench was purposely built up that consists of a water chiller, an air handling unit and a heat and mass transfer section.

The air handling unit is used to control the air flow conditions in terms of flow rate, temperature and relative humidity. It consists of water cooled and electrical heating sections, with capacities of $3 \mathrm{~kW}$ and $8 \mathrm{~kW}$ respectively, and an evaporating package. The fan is provided with an inverter to be driven continuously to control the air flow rate, read by a flowmeter.

The air operating conditions are set by the user and controlled through a PID, placed on the board panel; the effective values are measured by a thermo-hygrometer.

The cooling water is sent to a chiller, condensed by air, with a nominal capacity of $4 \mathrm{~kW}$.

The air is totally recirculated from the test section to the handling unit and air ducts include curve portions and restrictions.
The core of the test experimental setup is the heat and mass heat transfer section, made up of a rectangular transparent channel $\left(450 \times 200 \times 1800 \mathrm{~mm}^{3}\right)$ with a heat transfer geometry of staggered tubes. The refrigerant is simulated with three electrical heaters provided with Pt100 Resistance Temperature Detectors for the measurement of the outer surface temperature. This temperature is kept constant to the desired value by a PID controller.

The remaining tubes establish in the test section a fluid dynamic field very similar to the one in the real device.

Water is taken from the basin and sent by the circulator to three tubes that distribute it over the electrical heaters.

Water temperature is measured by a Pt100 RTD and adjusted with an electrical heater placed in the basin, while the mass flow rate is read by an electromagnetic flowmeter and controlled either through a three-way valve and by varying the pump speed.

The basin level is controlled by a float valve allowing the sprayed water make-up.

The heat transfer rejection from the electrical heaters to air is improved by water evaporation.

The effective moist air conditions before and after the heat and mass transfer interaction with electrical heaters are measured by two thermo-hygrometers.

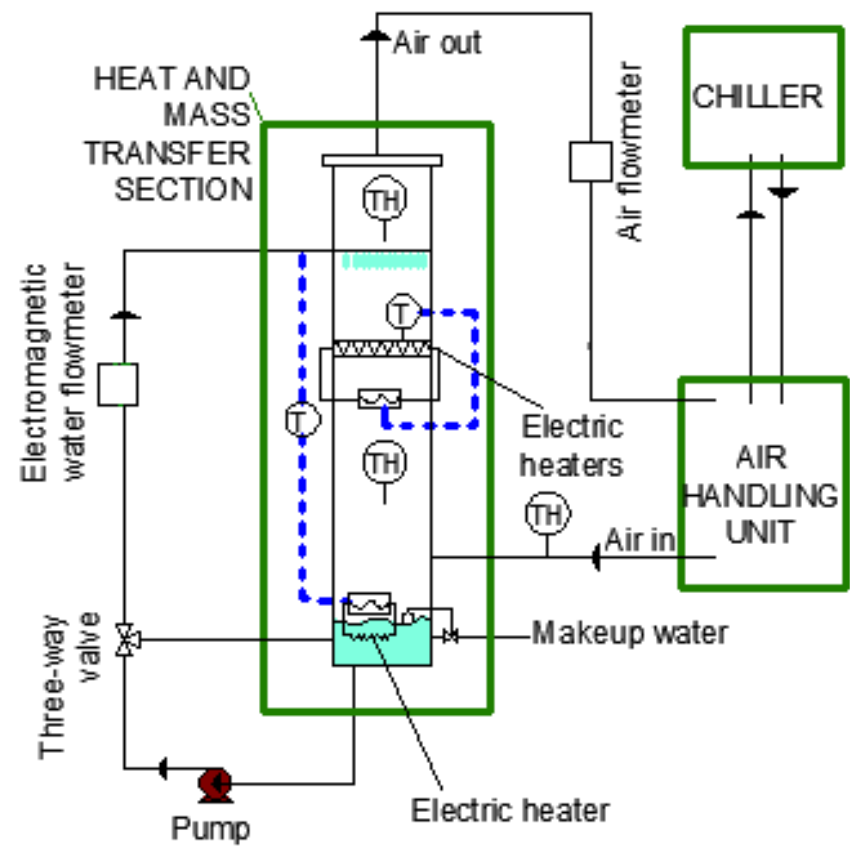

Figure 1. Experimental set-up (T: Thermo-regulator-TH: Thermo-hygrometer)

\subsection{The methodology}

The parameters set up by the user are:

1. air flow rate;

2. dry bulb temperature and relative humidity of air entering the heat and mass transfer section;

3. temperature and mass flow rate of water distributed over the electrical heaters;

4. outer surface temperature of the electrical heaters.

After a steady-state regime has been reached, the system performance is evaluated based on the following parameters: 
1. air dry bulb and relative humidity before the interaction with the electrical heaters. Actually, they are not perfectly the same as those set by the user, as an air cooling occurs in the channel portion between the basin and the electrical heaters caused by the interaction with water falling down from the test section.

2. air dry bulb and relative humidity after the interaction with the electrical heaters.

\subsection{The measurements}

The instrumentation provided for reading the physical quantities is reported in Table 1.

The maximum relative uncertainties are summarized in Table 2.

Table 1. The test bench instrumentation

\begin{tabular}{cc}
\hline Physical quantity & Instrument \\
\hline Air flow rate & $\begin{array}{c}\text { Differential pressure } \\
\text { transducer }\end{array}$ \\
\hline $\begin{array}{c}\text { Air dry bulb temperature and } \\
\text { relative humidity }\end{array}$ & Thermo-hygrometer \\
\hline Water mass flow rate & $\begin{array}{c}\text { Electromagnetic } \\
\text { flowmeter }\end{array}$ \\
\hline Water temperature & Pt100 RTD \\
\hline $\begin{array}{c}\text { Outer surface temperature of } \\
\text { electrical heaters }\end{array}$ & Pt100 RTD \\
\hline
\end{tabular}

Table 2. Maximum uncertainties

\begin{tabular}{cc}
\hline Physical quantity & Uncertainty \\
\hline Air flow rate & $\pm 5 \%$ \\
\hline Air dry bulb temperature & $\pm 1 \%$ \\
\hline Air relative humidity & $\pm 4 \%$ \\
\hline Water mass flow rate & $\pm 5 \%$ \\
\hline Water temperature & $\pm 1 \%$ \\
\hline $\begin{array}{c}\text { Outer surface temperature of } \\
\text { electrical heaters }\end{array}$ & $\pm 1 \%$ \\
\hline
\end{tabular}

\subsection{The theoretical analysis}

The measured dry bulb temperature and relative humidity were used to determine the moist air specific humidity and density as follows:

$b=\frac{7066.27}{T_{d b}+273.15}-5.976 \ln \left(T_{d b}+273.15\right)$

$p_{\text {sat }}=e^{b}$

$x_{\text {air }}=0.622 \phi_{\text {air }} \frac{p_{\text {sat }}}{p_{a m b}-\phi_{\text {air }} p_{\text {sat }}}$

$\rho_{\text {air }}=\frac{0.622 \cdot p_{a m b}}{R_{a i r}\left(T_{d b}+273.15\right)\left(0.622+x_{\text {air }}\right)}$

The air mass flow rate was calculated as the product of the air density at the outlet of the handling unit and the volumetric flow rate:

$\dot{m}_{\text {air }}=\dot{G} \cdot \rho_{\text {air,setpoint }}$

The mass flow rate of dry air is: $\dot{m}_{d a}=\frac{\dot{m}_{\text {air }}}{1+x_{\text {air,setpoint }}}$

The specific enthalpy was determined as:

$h_{\text {air }}=1.005 \cdot T_{d b}+x_{\text {air }} \cdot\left(1.9 \cdot T_{d b}+2500\right)$

The knowledge of the enthalpy difference between inlet and outlet sections allowed to evaluate the heat rejected to air, by assuming the water temperature variation as negligible:

$\dot{Q}=\dot{m}_{d a}\left(h_{\text {air,out }}-h_{\text {air,in }}\right)$

The evaporated water depends on the specific humidity variation as follows:

$\dot{m}_{\text {evap,water }}=\dot{m}_{d a}\left(x_{\text {air }, \text { out }}-x_{\text {air,in }}\right)$

\section{RESULTS AND DISCUSSIONS}

\subsection{The influence of the relative humidity}

The effect of relative humidity has been investigated by varying its set point value in the range $[50 \div 90] \%$, while other factors have been kept constant during the experiments, as summarized in Table 3 .

Table 3. Test operating conditions (Case A)

\begin{tabular}{cc}
\hline Parameter & Value \\
\hline $\boldsymbol{T}_{\text {wall }},{ }^{\circ} \mathrm{C}$ & 28 \\
\hline$\dot{\boldsymbol{G}}_{\text {water }}, 1 \cdot \mathrm{min}^{-1}$ & 1.2 \\
\hline $\boldsymbol{T}_{\text {water }},{ }^{\circ} \mathrm{C}$ & 26 \\
\hline$\dot{\boldsymbol{G}}_{\text {air }}, \mathrm{m}^{3} \cdot \mathrm{h}^{-1}$ & 800 \\
\hline $\boldsymbol{T}_{\boldsymbol{d b} \text {, setpoint }},{ }^{\circ} \mathrm{C}$ & 23 \\
\hline $\boldsymbol{R H}_{\text {setpoint }}, \%$ & {$[50-60-70-80-90]$} \\
\hline
\end{tabular}

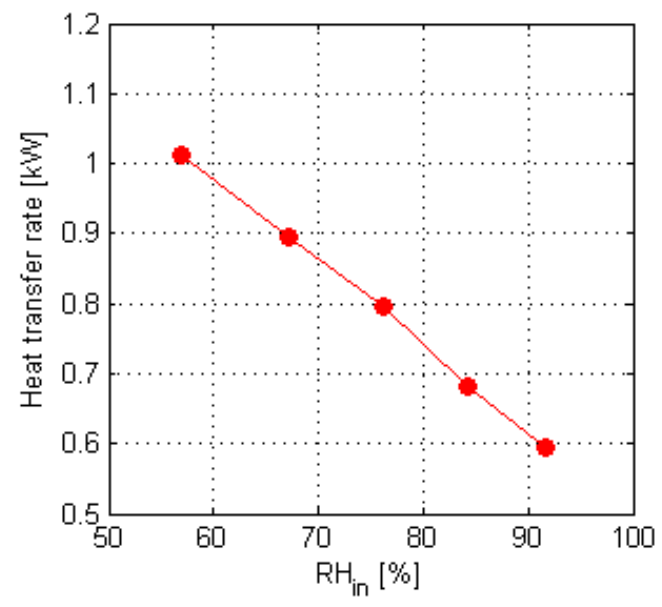

Figure 2. Heat transfer rate trend with relative humidity (Case A)

In Figure 2 the average values of heat transfer rate depending on the relative humidity measured before the electrical heaters are represented.

The heat rejected to air decreases with relative humidity because of the latent contribution to the heat transfer decrease. 
The heat transfer rate reduction is more significant at higher humidity, as the analysis of the curve slope suggests.

An increase of $10 \%$ of the relative humidity initial value at the first range leads to a cooling capacity reduction of $12 \%$, while in the last range, the same reduction amount is caused by a variation of relative humidity of $8 \%$.

Actually, the amount of evaporated water gets half of the initial value when the relative humidity changes from $57 \%$ to $92 \%$, as illustrated in Figure 3.

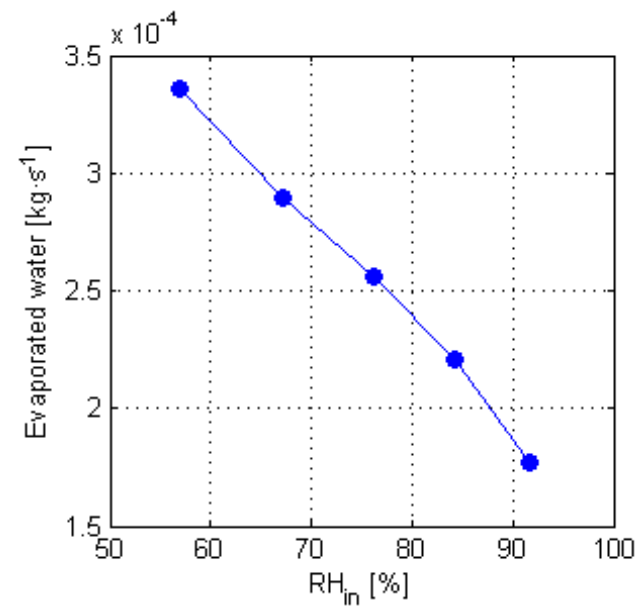

Figure 3. Evaporated water trend with relative humidity (Case A)

\subsection{The influence of the dry bulb temperature and the relative humidity}

The combined effect of relative humidity and dry bulb temperature has been analyzed, at the operating conditions reported in Table 5 .

The heat transfer rate versus the inlet relative humidity for three different levels of dry bulb temperature is shown in Figure 4.

The heat rejected to air decreases with both relative humidity and dry bulb temperature as the driving force of the evaporative cooling is the difference between the condensing and the wet bulb temperature.

The line becomes steeper at higher dry bulb temperature.

The lines corresponding to dry bulb temperatures of $23{ }^{\circ} \mathrm{C}$ and $25{ }^{\circ} \mathrm{C}$ appear parallel for a relative humidity lower than $90 \%$, while, for values higher than $90 \%$, the distance between them increases. When the relative humidity is $97 \%$ an increase of $9 \%$ of the dry bulb temperature causes a heat transfer rate reduction of $46 \%$.

Table 4. Test operating conditions (Case B)

\begin{tabular}{cc}
\hline Parameter & Value \\
\hline $\boldsymbol{T}_{\text {wall }},{ }^{\circ} \mathrm{C}$ & 28 \\
\hline$\dot{\boldsymbol{G}}_{\text {water }}, 1 \cdot \mathrm{min}^{-1}$ & 3 \\
\hline $\boldsymbol{T}_{\text {water }},{ }^{\circ} \mathrm{C}$ & 26 \\
\hline$\dot{\boldsymbol{G}}_{\text {air }}, \mathrm{m}^{3} \cdot \mathrm{h}^{-1}$ & 800 \\
\hline $\boldsymbol{T}_{\boldsymbol{d b} \text {,setpoint }},{ }^{\circ} \mathrm{C}$ & {$[19-23-25]$} \\
\hline $\boldsymbol{R H}_{\text {setpoint }}, \%$ & {$[70-80-90]$} \\
\hline
\end{tabular}

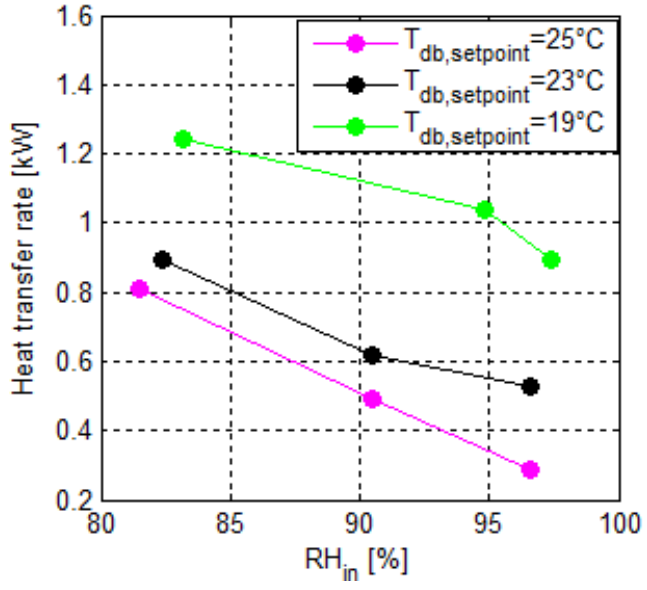

Figure 4. Heat transfer rate trend with relative humidity and dry bulb temperature (Case B)

\subsection{The influence of the deluge water temperature and the relative humidity}

Test conditions reported in Table 5 have been adopted to analyze the influence of the deluge water temperature on the heat transfer rate, represented in Figure 5.

Table 5. Test operating conditions (Case C)

\begin{tabular}{cc}
\hline Parameter & Value \\
\hline $\boldsymbol{T}_{\text {wall }},{ }^{\circ} \mathrm{C}$ & 28 \\
\hline$\dot{\boldsymbol{G}}_{\text {water }}, 1 \cdot \mathrm{min}^{-1}$ & 3 \\
\hline $\boldsymbol{T}_{\text {water }},{ }^{\circ} \mathrm{C}$ & {$[25-26]$} \\
\hline$\dot{\boldsymbol{G}}_{\text {air }}, \mathrm{m}^{3} \cdot \mathrm{h}^{-1}$ & 800 \\
\hline $\boldsymbol{T}_{\boldsymbol{d} \text {,setpoint }},{ }^{\circ} \mathrm{C}$ & 23 \\
\hline $\boldsymbol{R H}_{\text {setpoint }},{ }^{\circ}$ & {$[60-70-80-90]$} \\
\hline
\end{tabular}

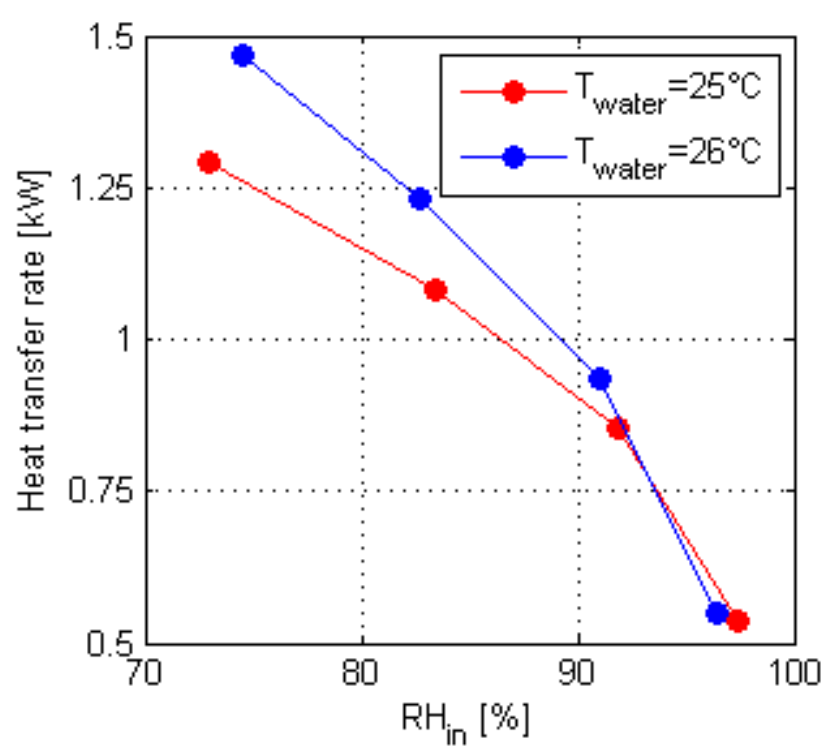

Figure 5. Heat transfer rate vs. relative humidity and water temperature (Case C) 


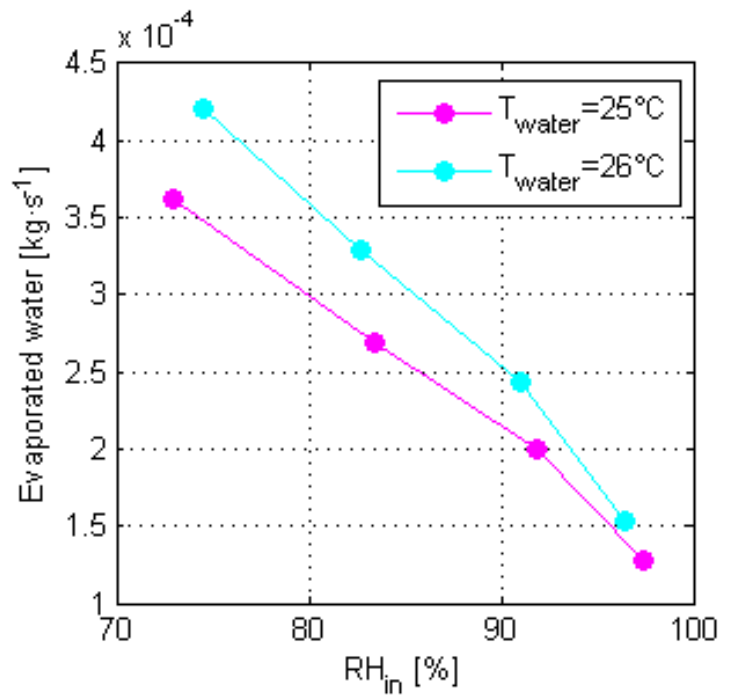

Figure 6. Amount of evaporated water vs. relative humidity and water temperature (Case C)

The water temperature improves the heat rejection from the electrical heaters, because the amount of evaporated water depends on the difference between the saturated vapor pressure evaluated at water temperature and the vapor pressure of the surrounding air.

As a consequence, the improving influence of the water temperature on the heat transfer is more significant at lower values of relative humidity, while it becomes negligible when the air is close to saturation.

The heat transfer rises due to an increase of $6 \%$ of the water temperature at different relative humidity levels are $14 \%, 14 \%, 9.8 \%$ and $2.3 \%$ respectively.

The heat transfer rate trend reflects that of the evaporated water, shown in Figure 6.

\subsection{The influence of the water flow rate}

The trend of heat transfer rate with the water flow rate has been investigated too.

The graph in Figure 7 is referred to the operating conditions reported in Table 7.

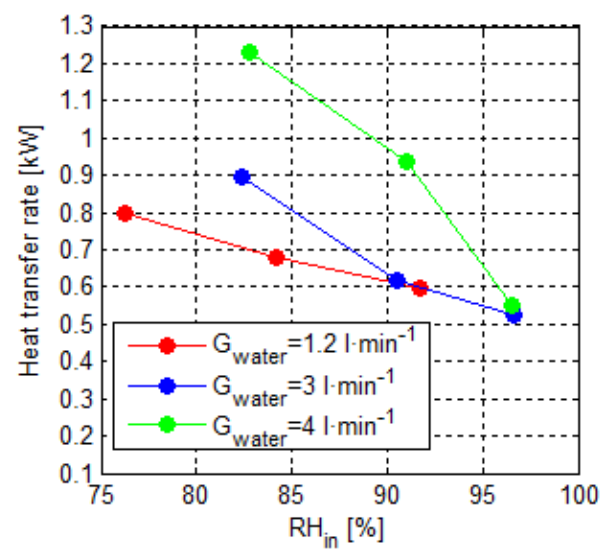

Figure 7. Effect of the water flow rate on the heat transfer rate (Case D)

Generally, it can be stated that the cooling capacity increases with the water flow rate fed into the test heat and mass transfer section at lower relative humidity, while it can be considered constant when the air reaches the saturation.
An increasing water flow rate from 1.2 to $3 \mathrm{l} / \mathrm{min}$ involves a higher heat transfer only for a relative humidity value lower than $90 \%$. When the entering water flow rate is $4 \mathrm{l} / \mathrm{min}$ the system is characterized by better performance for all relative humidity levels, except for those close to saturation.

Table 6. Test operating conditions (Case D)

\begin{tabular}{cc}
\hline Parameter & Value \\
\hline $\boldsymbol{T}_{\text {wall }},{ }^{\circ} \mathrm{C}$ & 28 \\
\hline$\dot{\boldsymbol{G}}_{\text {water }}, 1 \cdot \mathrm{min}^{-1}$ & {$[1.2-3-4]$} \\
\hline $\boldsymbol{T}_{\text {water }},{ }^{\circ} \mathrm{C}$ & 26 \\
\hline$\dot{\boldsymbol{G}}_{\text {air }}, \mathrm{m}^{3} \cdot \mathrm{h}^{-1}$ & 800 \\
\hline $\boldsymbol{T}_{\boldsymbol{d b} \text { setpoint }},{ }^{\circ} \mathrm{C}$ & 23 \\
\hline $\boldsymbol{R H}_{\text {setpoint }}, \%$ & {$[70-80-90]$} \\
\hline
\end{tabular}

\section{CONCLUSIONS}

In this paper, a sensitivity analysis on the air side heat and mass transfer phenomena occurring in evaporative condenser was presented based on an experimental campaign.

A test bench was purposely designed in order to control all the parameters affecting the system performance.

An air handling unit supplying humid air to the test section allows to control air flow rate, temperature and relative humidity.

In the test chamber, electrical heaters are placed to simulate at a tube scale the real geometry and the actual condensing refrigerant conditions by keeping constant at the desired values their outer surface temperatures.

During the experimental campaign, the temperature of electrical heaters and air flow rate were kept at fixed values, while the influence of the other parameters was analyzed.

The most significant heat transfer rate decrease with the relative humidity and the dry bulb temperature was observed at the highest values of wet bulb temperature, as was expected.

The cooling capacity improved with the water flow rate and the temperature, except when the air was close to saturation. An increase of $6 \%$ of the water temperature led to a maximum performance improvement of $14 \%$. In terms of water flow rate, the maximum benefit deriving from its $15 \%$ increase is of $31 \%$.

The test rig offers the possibility to explore different combinations of the affecting parameters for a specific heat transfer geometry, and, as a consequence, to obtain predicting relationships of the system behavior.

A further additional advantage is that geometries with different tube diameters and distance between them can be analyzed and then compared with respect to heat and mass transfer local performance.

\section{REFERENCES}

[1] Parker R.O., Treybal R.E. (1961). The heat mass transfer characteristics of evaporative coolers, Chemical Engineering Progress Symposium, Vol. 57, No. 32, pp. 138-149.

[2] Mizushina T., Ito R., Miyashita H. (1967). Experimental study of an evaporative cooler, International Chemical 
Engineering., Vol. 7, No. 4, pp. 727-732.

[3] Kreid D.K., Johnson B.M., Faletti D.W. (1978). Approximate analysis of heat transfer from the surface of a wet finned heat exchanger, ASME paper, 78-HT26.

[4] Leidenfrost W., Korenic B. (1982). Evaporative cooling and heat transfer augmentation related to reduced condenser temperatures, Heat Transfer Engineering, Vol. 3, No. 3, pp. 38-59. DOI: $\underline{10.1080 / 01457638108939583}$

[5] Bykov A.V., Gogolin V.A., Tovaras N.V. (1984). Investigation of heat, mass transfer and fluid flow characteristics in evaporative condensers, International Journal of Refrigeration, Vol. 7, No. 6, pp. 342-347. DOI: 10.1016/0140-7007(84)90003-3

[6] Webb R.L. (1984). A unified theoretical treatment for thermal analysis of cooling towers, evaporative condensers and fluid coolers, Conference ASHRAE Transactions, Vol. 90, No. 2, pp. 398-415.

[7] Erens J., Dreyer A.A. (1988). An improved procedure for calculating the performance of evaporative closedcircuit coolers, Conference The 25th National Heat Transfer Conference, Houston, AIChE Symposium Series, Vol. 84, pp. 140-145.

[8] Zalewski W., Gryglaszewski P.A. (1997). Mathematical model of heat and mass transfer processes in evaporative fluid coolers, Chemical Engineering and Processing: Process Intensification, Vol. 36, No. 4, pp. 271-280. DOI: 10.1016/S02552701(97)00006-8

[9] Ettouney H.M., El-Dessouky H.T., Bouhamra W., AlAzmi B. (2001). Performance of evaporative condensers, Heat Transfer Engineering, Vol. 22, No. 4, pp. 41-55. DOI: 10.1080/01457630119438

[10] Qureshi B.A., Zubair S.M. (2005). The impact of fouling on performance evaluation of evaporative coolers and condensers, International Journal of Energy Research, Vol. 29, No. 14, pp. 1313-1330. DOI: $\underline{10.1002 / \text { er. } 1120}$

[11] Qureshi B.A., Zubair S.M. (2006). A comprehensive design and rating study of evaporative coolers and condensers. Part I. Performance evaluation, International Journal of Refrigeration, Vol. 29, No. 4, pp. 645-658. DOI: 10.1016/j.ijrefrig.2005.09.014

[12] Qureshi B.A., Zubair S.M. (2006). A comprehensive design and rating study of evaporative coolers and condensers, Part II. sensitivity analysis, International Journal of Refrigeration, Vol. 29, No. 4, pp. 659-668. DOI: 10.1016/j.ijrefrig.2005.09.015

[13] Hajidavalloo E., Eghtedari H. (2010). Performance improvement of air-cooled refrigeration system by using evaporatively cooled air condenser, International Journal of Refrigeration, Vol. 33, No. 5, pp. 982-988. DOI: $10.1016 /$ j.ijrefrig.2010.02.001

[14] Jahangeer K.A., Tay A.A., Islam M.R. (2011). Numerical investigation of transfer coefficients of an evaporatively-cooled condenser, Applied Thermal Engineering, Vol. 31, No. 10, pp. 1655-1663. DOI: 10.1016/j.applthermaleng.2011.02.007

[15] Tissot J., Boulet P., Trinquet F., Fournaison L., Lejeune M., Liaudet F. (2014). Improved energy performance of a refrigerating machine using water spray upstream of the condenser, International

Journal of Refrigeration, Vol. 38, pp. 93-105. DOI: 10.1016/j.ijrefrig.2013.08.025

[16] Islam M.R., Jahangeer K.A., Chua K.J. (2015). Experimental and numerical study of an evaporatively-cooled condenser of air-conditioning systems, Energy, Vol. 87, pp. 390-399. DOI: 10.1016/j.energy.2015.05.005

[17] Fiorentino M., Starace G. (2016). Numerical investigations on two-phase flow modes in evaporative condensers, Applied Thermal Engineering, Vol. 94, pp. 777-785. DOI: 10.1016/j.applthermaleng.2015.10.099

[18] Junior I.C., Smith-Schneider A.P. (2016). Consolidated experimental heat and mass transfer database for a reduced scale evaporative condenser, International Journal of Refrigeration, Vol. 66, pp. 21-31. DOI: $\underline{10.1016 / \text { j.ijrefrig.2015.12.006 }}$

[19] Liu H., Zhou Q., Liu Y., Wang P., Wang D. (2015). Experimental study on cooling performance of air conditioning system with dual independent evaporative condenser, International Journal of Refrigeration, Vol. 55, pp. 85-92. DOI: 10.1016/j.ijrefrig.2015.03.012

[20] Fiorentino M., Starace G. (2016). Numerical and experimental performance analysis of evaporative condensers, Energy Procedia, Vol. 101, pp. 26-33. DOI: $\underline{10.1016 / \text { j.egypro.2016.11.004 }}$

\section{NOMENCLATURE}

$b$

$\dot{G}$

$h$

$\dot{m}$

$p_{a m b}$

$p_{\text {sat }}$

$\dot{Q}$

$R_{\text {air }}$

RH

RTD

$T$

$x$

\section{Greek symbols}

$\rho$

\section{Subscripts}

$\begin{array}{ll}\text { air } & \text { Air } \\ d a & \text { Dry air } \\ d b & \text { Dry bulb } \\ \text { evap,water } & \text { Evaporated water } \\ \text { in } & \text { Conditions before the electrical heaters } \\ \text { out } & \text { Conditions after the electrical heaters } \\ \text { setpoint } & \text { Set conditions at the outlet of the air } \\ & \text { handling unit. } \\ \text { wall } & \text { Surface of electrical heaters } \\ \text { water } & \text { Water }\end{array}$

Coefficient, -

Volumetric flow rate, $\mathrm{m}^{3} \cdot \mathrm{h}^{-1}$ (for air); $1 \cdot \mathrm{min}^{-1}$ (for water)

Specific enthalpy, $\mathrm{kJ} \cdot \mathrm{kg}_{\mathrm{da}}{ }^{-1}$

Mass flow rate, $\mathrm{kg} \cdot \mathrm{s}^{-1}$

Ambient pressure, $\mathrm{Pa}$

Saturated vapor pressure, $\mathrm{Pa}$

Heat transfer rate, $\mathrm{kW}$

Air gas constant, $\mathrm{J} \mathrm{kg}^{-1} \mathrm{~K}^{-1}$

Relative humidity, \%

Resistance Temperature Detector

Temperature, ${ }^{\circ} \mathrm{C}$

Specific humidity, $\mathrm{kg} \cdot \mathrm{kg}_{\mathrm{da}}{ }^{-1}$

Density, $\mathrm{kg} \cdot \mathrm{m}^{-3}$

Psychrometric ratio, - 